Abstract

Objective-To study the acquisition of tobacco and the development of cigarette brand selection among youth. To compare four methods of measuring brand preference among underage smokers.

Design - Individual interviews were conducted with youths to elicit their past and present experiences with tobacco.

Setting - A high school and public places in Massachusetts, USA.

Subjects - A convenience sample of 721 youths, aged 10-17 years.

Results - Friends were the source of the subject's first cigarette in $69 \%$ of cases. Fifty per cent of the subjects were smoking three or fewer cigarettes per day when they first purchased tobacco. The first brand smoked was the first regular brand chosen in $67 \%$ of cases, and $51 \%$ of smokers were still smoking the same brand as their first cigarette. Ultra-low tar and generic brands were unpopular among youths. Questions concerning the favourite brand, brand usually purchased, last brand smoked, and friend's favourite brand produced very similar brand preference results for full-priced brands. However, only the question concerning the last brand smoked seemed to assess the use of generic brands accurately.

University of

Massachusetts

Medical Center,

Fitchburg,

Massachusetts, USA

JR DiFranza

University of

Massachusetts

Medical School

Worcester,

Massachusetts, USA

JJ Eddy

LF Brown

Assumption College,

Worcester,

Massachusetts, USA

JL Ryan

Center for Marketing

Research,

Fitchburg,

Massachusetts, USA

A Bogojavlensky

Correspondence to JR DiFranza, University of Massachusetts Medical Center, 47 Ashby State Road, Fitchburg, MA 01420 , USA tobacco to minors, dramatic reductions in the prevalence of smoking have been seen among young adolescents. ${ }^{3,4}$ Efforts to reduce minors' access to tobacco have raised a number of questions. Where does the purchase of tobacco

\section{Tobacco acquisition and cigarette brand selection among youth}

Joseph R DiFranza, Jennifer J Eddy, Linda F Brown, Jennifer L Ryan, Ann Bogojavlensky fit in the process of becoming a regular smoker? What prompts children to first attempt to purchase tobacco and what strategies do they use? What role do parents and cigarette vending machines play in making cigarettes accessible? Is there an underage "black market" for cigarettes? Is shoplifting common? A detailed understanding of when and how children obtain tobacco may facilitate efforts to reduce their access to tobacco.

Unpublished tobacco industry research has suggested that brand preference is often established with a child's first cigarette. ${ }^{5}$ If this is true, the tobacco company most successful at reaching the youngest children has an obvious advantage in the battle over market share. The RJ Reynolds Tobacco Company has demonstrated recent success in this regard. The proportion of underage smokers naming Reynolds' Camel cigarettes as their favourite brand rose from $0.5 \%$ prior to the introduction of Camel cartoon advertisements in 1988 , to $32.8 \%$ by early $1991 .^{6}$ A $32.8 \%$ share of the USs' children's cigarette market segment is worth $\$ 476$ million per year in sales. ${ }^{6,7} \mathrm{RJ}$ Reynolds has challenged the assumption that young smokers actually purchase and smoke the brands they name as their favourites. ${ }^{8}$ They have also challenged the assumption that children have favourite brands, and the assumption that the brands smoked by children with favourite brands are representative of the brands smoked by youngsters who do not have a stated brand preference..$^{6,9}$

Additional objectives of this investigation selection among youths, and to assess the comparability of four methods of assessing brand share in the children's market segment.

\section{Methods}

During individual interviews, 721 youths were asked about their previous and current experiences with tobacco. The study was conducted in two parts to accommodate the educational responsibilities of the junior authors. During the summer of 1992, 383 interviews were conducted with youths $10-17$ years of age using a consumer intercept marketing survey procedure in locations frequented by youths during their school vacations. The vast majority of the interviews were conducted in shopping malls, while a few were conducted in parks and at the beach. The shopping malls were located in two lower were to investigate the development of brand

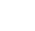

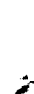

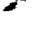

$\because$

$\Rightarrow$

$\because$

5

$\checkmark$

$z$ 
socio-economic status urban areas where Puerto Ricans are the predominant ethnic minority group. More than $90 \%$ of the youths who were approached agreed to participate.

During the autumn of 1993, an additional 338 interviews were conducted with 9 th and 10th grade students at a local high school which had large Puerto Rican and Southeast Asian populations. All of the students who had parental permission agreed to participate. As a result of active law enforcement, the community in which this high school is located has a high level of merchant compliance with the prohibition on tobacco sales to minors.

All interviews were conducted in Massachusetts, USA, where it is illegal to sell or provide tobacco to minors under 18 years of age, but where it is not illegal for minors to purchase, possess, or use tobacco.

Our sampling strategy produced a population with a bell-shaped age distribution with a range from 10 to 17 years and a mean of 14.5 years. Females made up $48.0 \%$ of the study population.

A letter explaining the study was sent to the parents of the high school students and they were asked to return the letter if they did not want their child to participate. Only one parent did so. For logistical reasons, it was not possible to obtain parental consent for the consumer intercept portion of the study. All subjects were asked to participate voluntarily in an anonymous survey concerning tobacco. If they agreed to participate they were interviewed individually by one of the authors $(\mathrm{JJE}$, JLR, LFB). The study was approved by the Committee for the Protection of Human Subjects at the University of Massachusetts Medical Center.

The consumer intercept technique is frequently used in market research and has been used by the tobacco industry to study youth access to tobacco. ${ }^{10}$ The interviewer, equipped with a clipboard and name tag, waits in a public place and invites passers-by to answer questions on a particular topic.

Subjects were asked a series of questions concerning demographics and past and present use of tobacco products. "Never-smokers" had never puffed on a cigarette. "Experimenters" had smoked fewer than ten cigarettes during their lifetime. Subjects were categorised as "ever-smokers" if they had smoked ten or more cigarettes in their lifetime. A "yes" answer to the question "Do you smoke now, even once in a while?" further categorised the subject as a "current smoker", while a "no" answer categorised the subject as an exsmoker. Ever-smokers were asked the age at which they began to smoke "regularly" but this term was not defined for them. Questions concerning spitting tobacco produced numbers too small to report. The authors used 10 cigarettes as the cutoff for the definition of "experimenters", rather than the more common measure of 100 , because our interest is in the earliest smoking experiences and we did not want to exclude subjects who had smoked only briefly.

Only current smokers were asked about their current sources of tobacco and brand preferences. All results are based on selfreport without independent confirmation; $95 \%$ confidence intervals (CIs) were computed where appropriate.

\section{Results}

The denominators for our results change from question to question because some of our questions were applicable only to subsets of the subjects, and some subjects were unable to recall all of the details of their early experiences with tobacco.

Of 721 subjects, $373(51.7 \%)$ had never smoked, $177(24.5 \%)$ had only experimented, $43(6 \%)$ were ex-smokers, and $128(17.8 \%)$ were current smokers.

In this population, the mean age for the first puff on a cigarette was 12.0 years (range $4-17$ ). The source of the first cigarette was reported by 345 of the 348 subjects who had puffed on a cigarette. Friends were the major source $(69 \%)$, followed by stealing from parents $(11 \%)$, getting them from siblings $(8 \%)$, being given them by parents $(3 \%)$, buying them $(3 \%)$, and stealing them from other sources $(2 \%)$.

Ever-smokers $(\mathrm{n}=171)$ were asked if they had ever obtained cigarettes from specific sources. Friends had been a source for $99 \%$, and siblings a source for $43 \%$. A parent had given cigarettes to $25 \%$ of the subjects, while $38 \%$ of the subjects reported having stolen them from parents, $47 \%$ had stolen them from someone other than their parent, $23 \%$ reported stealing them from a store, and $66 \%$ had given money to someone else to buy cigarettes for them because they were unable to do so themselves.

To determine if a black market exists for cigarettes, we asked the smokers if they knew of other children selling tobacco for a profit, and $48 \%$ indicated they were aware of this happening. Several subjects indicated that peers were selling packets for one dollar each - far below their retail price.

Tobacco had been purchased by $71 \%$ of the ever-smokers $(n=171)$. Subjects were asked why they decided to purchase their first pack $(\mathrm{n}=120)$. The most common answer $(32 \%)$ was that either they were tired of asking for cigarettes or their friends were tired of them asking for cigarettes. Nineteen per cent stated that they began to purchase cigarettes to satisfy an addiction.

All four questions concerning the timing of the initial purchase of tobacco and the onset of experimental and regular smoking were answered by 112 subjects. In this subset, the mean age for the first puff on a cigarette was 11.3 years, for the first purchase of tobacco, 12.8 years, and for the onset of self-reported regular smoking, 13.0 years. Subjects who had purchased tobacco were asked how many weeks had elapsed between the first puff and first purchase $(n=121)$. For $6.6 \%$ of subjects the first purchase preceded the first puff, while $50 \%$ had purchased tobacco either before or within 10 weeks after the first puff. Fifty per 
cent were smoking three or fewer cigarettes per day when they made their first purchase $(\mathbf{n}=$ 116). These analyses necessarily exclude smokers who had never purchased tobacco or never smoked regularly.

Convenience stores were the most common location of the first purchase $(65 \%)$, followed by vending machines $(12 \%)$ and gas (petrol) stations $(11 \%)(n=120)$. Of the 89 subjects who had purchased tobacco from a vending machine, $44 \%$ said that they had done so because they were unable to buy tobacco elsewhere.

The first brand smoked could be recalled by 285 subjects. While more than 17 brands were represented, Marlboro accounted for $47 \%$, Newport for $25 \%$, Camel for $5 \%$, and Winston for $4 \%$. Each of the remaining brands accounted for less than $2 \%$ of the responses. The first brand smoked is largely determined by the source of the first cigarette, with the smoker frequently having little choice.

There were 147 subjects who had smoked regularly at some time, and all but one had adopted a regular brand. The first regular brand was identical to the brand of the first cigarette smoked $67 \%$ of the time. While more than 17 brands were listed as the subjects' first cigarette, only eight were listed as the first regular brand smoked, and three brands Marlboro, Newport, and Camel-accounted for $94 \%$ of the responses. Of 128 current smokers, $51 \%$ said that the brand of their first cigarette was their current favourite, and $65 \%$ said that their first regular brand was their current favourite.

Youngsters maintained brand loyalty despite experimentation with other brands. Eversmokers $(n=170)$ had tried a mean of 5.6 brands (range 1-30). The Marlboro brand had been tried by $95 \%$ of subjects, Newport by $80 \%$, Camel by $58 \%$, and Winston by $48 \%$.

Responses to the following four questions regarding brand choice were compared: "What brand was the last cigarette you smoked?", "Which brand do you buy most often?", "Do you have a favourite brand; if so, what is it?", and "What brand does your closest friend who smokes smoke?". The responses to all four questions were very similar (see table).

Ninety-eight subjects gave responses to each of the first three questions which concerned their own brand use, making a comparison of the responses to these questions possible. The favourite brand and the brand usually bought were identical for 90 subjects $(92 \%)(\mathrm{CI}=$ $0.85-0.96)$. The favourite brand was the last brand smoked for 69 subjects $(70 \%)(\mathrm{CI}=$

Table $A$ comparison of four methods for determining cigarette brand preferences among youths

\begin{tabular}{lcccc}
\hline & $\begin{array}{c}\text { Last } \\
\text { brand } \\
\text { smoked }\end{array}$ & $\begin{array}{c}\text { Brand } \\
\text { usually } \\
\text { bought }\end{array}$ & $\begin{array}{c}\text { Favourite } \\
\text { brand }\end{array}$ & $\begin{array}{c}\text { Brand of } \\
\text { closest } \\
\text { friend }\end{array}$ \\
\hline $\mathrm{n}$ & 128 & 111 & 108 & 125 \\
Marlboro & $51 \%$ & $58 \%$ & $58 \%$ & $56 \%$ \\
Newport & $23 \%$ & $26 \%$ & $27 \%$ & $23 \%$ \\
Camel & $9 \%$ & $10 \%$ & $10 \%$ & $11 \%$ \\
Generics & $12 \%$ & $2 \%$ & $1 \%$ & $2 \%$ \\
Other & $5 \%$ & $4 \%$ & $4 \%$ & $7 \%$ \\
\hline
\end{tabular}

$0.61-0.79)$, and the brand usually bought was the last brand smoked for 73 subjects $(74 \%)$ $(\mathrm{CI}=0.65-0.82)$.

Only 20 of the 128 regular smokers $(16 \%)$ had no favourite brand. Among these subjects, $85 \%$ had last smoked Marlboro, Newport, or Camel, with generic brands accounting for the remaining $15 \%$. Although the numbers are small, the distribution was similar to that seen among youths who do have a brand preference, with the possible exception of an increased use of generics among youths with no favourite brand.

In a separate question, 128 current smokers were asked how often they smoke generic cigarettes. Only $6 \%$ responded that they smoked them "a lot", $66 \%$ smoked them occasionally, and $27 \%$ never smoked them. Several subjects indicated that they bought the cheaper generics only when they cannot afford their favourite brand.

Current smokers were asked to rate ultralow-tar, light, and regular strength cigarettes on a five-point scale with one representing "yuck", and five representing "great". The 108 subjects who had tried ultra-low-tar gave them a mean rating of 1.6 . The 124 subjects who had tried light cigarettes gave them a mean rating of 2.6 . The 128 who had tried regulars rated them at 4.1 .

The 107 subjects who had favourite brands were asked why they chose them. The most commonly volunteered response was "taste" ( $46 \%$ ) followed by "I'm used to it" $(21 \%)$. A variety of other answers comprised the remaining $33 \%$. These included: "it doesn't kill you so much", "my idol smokes them", "cute cowboys" (Marlboro), "Camels are cool", "I like the colour of the package" (Marlboro), and "I like the box" (Camel). Only $4 \%$ of respondents volunteered that their friends' brands were a factor in their brand selection $(\mathrm{n}=128)$. Yet $58 \%$ of the time, the subject's favourite brand was the same as that smoked by their closest smoking friend $(n=128)$, and $67 \%$ of the time, the brand bought most often was the same as that smoked by the closest smoking friend $(\mathrm{n}=107)$.

When asked specifically, 128 current smokers identified the following factors as influencing their brand selection: taste $(78 \%)$, strength $(60 \%)$, availability $(52 \%)$, price $(34 \%)$, and what their friends smoke $(32 \%)$.

Thirty per cent $(n=127)$ indicated that they had purchased a particular brand to obtain a free promotional item such as a tee-shirt or lighter. Two-thirds of these were responding to a promotional offer for the Camel brand.

\section{Discussion}

Since the first purchase of tobacco usually occurs prior to the onset of regular smoking, interventions which stop the illegal sale of cigarettes to minors have the potential to halt the progression from experimentation to regular smoking in these young smokers.

While vending machines accounted for a small fraction of total sales to minors, they represent the weakest link in the defence 
against illegal sales, since $44 \%$ of the youths who had used vending machines had done so because they could not buy from other sources. If sales assistants were to abide by the law, vending machines could become a greater source of tobacco for youths.

Tobacco is the most commonly shoplifted product in retail stores. ${ }^{11}$ Some communities have banned self-service displays of tobacco products on the theory that they invite shoplifting by underage smokers. Of our underage smokers, $23 \%$ admitted to stealing cigarettes from stores. Although some youths were selling cigarettes to their peers, the fact that they were selling them below retail price argues that, in our community, this represented an outlet for shoplifted cigarettes rather than a way for underage smokers to get around the minimum age law.

Parents who smoke may undermine the efficacy of tobacco access law enforcement by acting as a source of tobacco for their children, either wittingly or unwittingly. It is disappointing that the parents of $25 \%$ of our underage smokers had given cigarettes to their children. In another study, $16.9 \%$ of ninthgrade smokers indicated that they usually obtain cigarettes from parents or other adults. ${ }^{1}$ Of the smokers in this study, $38 \%$ had stolen cigarettes from their parents. It is possible that the higher prevalence of smoking among the offspring of smokers may be due, in part, to their increased access to tobacco. It would be interesting to see if the discrepancy in smoking rates among the offspring of smoking and nonsmoking parents increases as illegal sales to children are curtailed.

Brand loyalty is usually established with the first cigarette smoked. The first brand tried was the first regular brand chosen $67 \%$ of the time. Although youngsters experiment with a variety of brands, $51 \%$ of our subjects were still smoking the same brand as their first cigarette. It is therefore of clear economic advantage to a tobacco company if the first brand smoked by a child is one of their brands.

Although only $4 \%$ of our subjects volunteered that their friends influenced their brand selection, $58 \%$ smoked the same brand as their closest smoking friend. We believe that this is due primarily to the high degree of loyalty to the initial brand smoked and the fact that friends are the most common source of the initial cigarette. By targeting advertising at youths who smoke, tobacco companies can effectively influence the brands available to first-time smokers.

RJ Reynolds' criticism ${ }^{8,9}$ of previous surveys ${ }^{6}$ for assuming that children have favourite cigarette brands and actually purchase them, seems unfounded. Regular smokers were found to have a favourite brand $84 \%$ of the time, and to purchase their favourite brand $92 \%$ of the time. Further, the actual brand use of those who do not have a favourite brand appears to parallel that of those who do. It is therefore reasonable to assume that the pattern of brand use among subjects who have favourite brands is representative of that of the entire survey population.
All four methods of measuring brand selection produced quite similar estimates of the use of the full-priced name-brands (see table). The reported use of generic brands was much higher in response to the question "what brand was the last cigarette you smoked?" than to any of the other three questions. Our subjects resorted to smoking generic brands $12 \%$ of the time, although these are neither their favourites nor what they usually buy. Youths frequently obtain cigarettes from their friends, and when this occurs they may end up smoking a brand that is neither their favourite nor what they would usually buy. We would conclude therefore, that with the recent introduction of generic brands, asking youths "what was the brand of the last cigarette you smoked?" produces the most accurate data on what they are actually smoking. However, previous surveys which inquired about brand preference should have produced reasonably accurate estimates of the use of full-priced brands.

In the US at the time of this study, the price of generic or "value-priced brands" was as low as one-half the price of the full-priced name-brands. In our population, generic brands accounted for only $12 \%$ of the cigarettes smoked by children at a time when they accounted for $28 \%-35 \%$ of all cigarette sales in the US. ${ }^{12,13}$ Our interviews made it clear that the vast majority of young smokers will smoke generic brands only as a last resort, explaining why generics barely register on brand preference surveys. This suggests that either youngsters are more concerned with the taste of their cigarettes than are adult smokers, or that, despite more limited finances, few youngsters are willing to sacrifice brand image for economy.

Concern has been raised over the possibility that very low tar cigarettes facilitate the uptake of smoking by youths by making it easier to smoke without feeling ill. We did not find evidence of this in that our subjects expressed a great distaste for very low tar cigarettes. By far, regular full-strength brands were preferred.

It would be illogical to conclude from our findings that children smoke primarily the $\frac{7}{0}$ Marlboro, Newport and Camel brands because other children smoke these brands. How would of one explain why children smoke these three $N$ brands and not three, or 30, others? Why do N $69 \%$ of teenage smokers smoke Marlboro, 0 when the overall market share for Marlboro is 0 only $26 \%$ ? $^{14}$ If peers are the primary influence on brand selection how would one explain the ? rapid 50 - to 60 -fold increase in the popularity of Camel cigarettes among underage smokers in the US ? ? $^{6,14,15}$

The tobacco industry describes children's brand selection as guided by the "herd in- 2 stinct". 5 We agree that when it comes to 8 cigarette brand preference children do behave like a herd, but the movement of the herd is guided primarily by the tobacco industry's marketing efforts. ${ }^{6,14,15}$ The present study adds to the already convincing evidence in this regard in that our subjects related making their 
brand selection based upon the influences of print advertising, free sampling, promotional items, package colour, package design, and the implied health benefits of low-tar brands.

Due to the unique ethnic and racial mix of our population, and recent efforts to prevent the sale of tobacco to minors in this community, caution should be used in generalising some of our findings to larger populations. In particular, no inferences can be made about the national pre-adult market share of particular brands based upon these data.

1 Cummings KM, Sciandra E, Pechacek TF, Orlandi M, Lynn WR. Where teenagers get their cigarettes: a survey of the purchasing habits of 13-16 year olds in 12 US communities. Tobacco Control 1992; 1: 264-7.

2 Forster JL, Klepp KI, Jeffery RW. Sources of cigarettes for tenth graders in two Minnesota cities. Health Educ Res $1989 ; 4: 45-50$

3 Jason LA, Ji PY, Anes MD, Birkhead SH. Active enforcement of cigarette control laws in the prevention of cigarette sales to minors. $\mathcal{F A M A} 1991$; 266 : 3159-61.
4 DiFranza JR, Carlson RP, Caisse RE. Reducing youth access to tobacco. Tobacco Control 1992; 1: 58.

5 Kwechansky Marketing Research Inc. Project 16, Report for Imperial Tobacco, 18 October 1977.

6 DiFranza JR, Richards JW, Paulman P, et al. RJR Nabisco's cartoon camel promotes Camel ct al. RJR Nabisco's cartoon camel promotes C

7 DiFranza JR. Tye JB. Who : $3149-53$. DiFranza JR, Tye JB. Who profits fro
children? $\mathcal{J} A M A$ 1990; 263: 2784-7.

8 Mizerski RW. Review of 11 December 1991 IAMA articles performed for Rf Reynolds Tobacco Company, 10 January 1992.

9 Beales JH. Analysis of studies reported in December 11, 1991 issue of $\mathcal{F} A M A$. Prepared for $\mathrm{RJ}$ Reynolds Tobacco Company, 24 January 1992.

10 Response Research, Inc. Findings for the study of teenage cigarette smoking and purchasing behavior. Prepared for the National Automatic Merchandising Association, June/July 1989, Chicago, Illinois.

11 ADWEEK, 16 December 1991: 10.

12 Philip Morris Companies. Press release, 16 July 1992.

13 PM/Quarterly, Third Quarter Report 1993, Philip Morris Companies Inc, New York, 25 October 1993.

14 Cummings KM, Sciandra E. Comparison of the cigarette brand preferences of adult and teenaged smokers brand preferences of adult and teenaged smokers United States, 1989, and 10 US commun
1990. MMWR 1992; 41: 171-3, 179-81.

15 Pierce JP, Gilpin E, Burns DM, et al. Does tobacco advertising target young people to start smoking? $\mathcal{F} A M A$ $1991 ; 266$ : 3154-8.

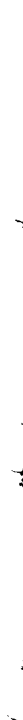

